\title{
Print versus Electronic Journal Use in Three Sci/Tech Disciplines: The Cultural Shift in Process
}

\section{Eileen E. Brady, Sarah K. McCord, and Betty Galbraith}

\begin{abstract}
This study examines journal use in three scientific disciplines. A previous study found that print use increased after electronic access was added. This article uses the same methods to determine if the increase in the use of the paper has continued. A cultural shift has happened between the two studies. Although the use of paper journals increased with the advent of e-journals, a shift in use patterns has occurred and patrons now favor electronic format. There are disciplinary differences in the use of paper and electronic formats. Most journal titles showing increases in print use also were available in electronic format.
\end{abstract}

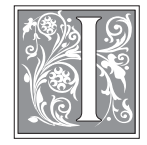

n September 2004, the results of a study evaluating the impact of the availability of electronic journals (e-journals) on the use of the print journals in the chemistry, mechanical and materials engineering (MME), and physics collections of the Owen Science and Engineering Library (Owen), Washington State University (WSU) were published. ${ }^{1}$ The authors were trying to determine if patrons were switching from print journals to electronic merely because a title was available electronically. Unsurprisingly, this study revealed that the use of all three collections had increased with the advent of electronic access to many of the titles. However, when comparing the years 1998, when there was no e-access, to usage in 2001, the statistics showed that, overall, the use of print collections increased after e-access was added.
As the original study was being conducted, the authors planned to revisit it in 2004 to determine if the marked increase in the use of the paper would continue. In the intervening years, the journal landscape became more complicated. "Big Deals" came and went or even changed in content. Inflation forced cancellations of journals, sometimes the print format, sometimes electronic, sometimes both. In many cases, print was cancelled in favor of electronic strictly for financial reasons. The library selectively purchased some new titles, but most new titles came from changes in the consortial packages that were purchased. The library also picked up journal back-runs and archives in electronic format. In the end, although data for 2004 are available, the reduced number of print journal subscriptions remaining in the collection did not pro-

Eileen E. Brady is Manager, Owen Science and Engineering Library Preservation and Access, and Security; Sarah K. McCord is the Electronic Resources Librarian in the Health Sciences Library; and Betty Galbraith is a Science Librarian and Instruction Coordinator in the Owen Science and Engineering Library at Washington State University: e-mail:brady@wsu.edu, mccord@wsu.edu, and bettyg@wsu.edu, respectively. 
vide a large enough sample from which to derive valid conclusions.

All these changes in the collection made statistical analysis based on the current collection problematic, because, for the first time, the library's collection changed yearly, based on e-journals available through consortial packages, "Big Deals", and other methods of bundling subscriptions. For this reason, it was decided to use only the titles that were in the earlier study in this follow-up. (See table 1.) Of the 316 titles in the original study, 177 remained by 2003 . Of these, 25 continued to be available only in print, 86 were electronic only, and 67 were available in both formats (See table 2.)

\section{Context}

Washington State University is a landgrant institution with eleven libraries on four campuses statewide. The Owen Library on the Pullman campus provides support to four thousand faculty and students with majors in the hard sciences, agriculture, and engineering as well as general undergraduate students in other majors.

\section{Questions}

The previous study revealed that the use of the paper collection had increased with the advent of e-journal access. This contradicted previously published findings that availability of e-journals decreased the use of comparable journals available

\begin{tabular}{|l|r|r|r|r|}
\hline \multicolumn{5}{|c|}{ TABLE 2 } \\
Formats of 2003 Sample, by Discipline \\
\hline \hline & Total & e-only & $\begin{array}{c}\text { Print } \\
\text { only }\end{array}$ & Both \\
\hline Chemistry & 66 & 36 & 4 & 26 \\
\hline MME & 46 & 16 & 20 & 10 \\
\hline Physics & 65 & 34 & 1 & 30 \\
\hline All & 177 & 86 & 25 & 67 \\
\hline $\begin{array}{l}\text { Note: Nearly half the titles in the study are available } \\
\text { only in electronic format, but different disciplines } \\
\text { show different percentages of print-only, electronic- } \\
\text { only, and dual-format journals. }\end{array}$ \\
\hline
\end{tabular}

\begin{tabular}{|l|c|c|}
\hline \multicolumn{3}{|c|}{$\begin{array}{c}\text { TABLE 1 } \\
\text { Changes in Number of Titles in } \\
\text { Sample, 1998-2003 }\end{array}$} \\
\hline \hline & $\mathbf{1 9 9 8}$ & $\mathbf{2 0 0 3}$ \\
\hline Chemistry & 90 & 66 \\
\hline MME & 105 & 46 \\
\hline Physics & 121 & 65 \\
\hline All & 316 & 177 \\
\hline $\begin{array}{l}\text { Note: Many titles examined in the original } \\
\text { study have been cancelled. In some cases, } \\
\text { electronic versions were retained, but titles } \\
\text { were removed from the current study because } \\
\text { electronic use statistics were not available. }\end{array}$ \\
\hline
\end{tabular}

only in paper. ${ }^{2,3,4}$ We wished to determine whether that trend would continue or, if the longer e-journals were available, whether the patterns seen at other institutions would assert themselves and the use of paper journals would decline.

\section{Methodology}

The authors compared the uses of chemistry, MME, and physics titles in 1998, before Owen had e-journals, to uses of the same titles in 2001, 2002 and 2003, when e-journals were available to users and use statistics were available from publishers. The previous article detailed the findings of the 1998-2001 comparison. As before, embargoed titles (those with time-delayed e-access) were not an issue; none were in the subject areas selected for the studies.

Continuous use statistics for paper journals have been kept at Owen since 1993. Each reshelving of a current or bound volume, whether checked out or used in-house, counted as one use. Signs posted throughout the library ask patrons not to reshelve items because a journal use study is being conducted. This has been going on long enough that faculty have learned that reshelving of issues instead of leaving them out to be counted could result in their journal being cancelled in the next round of cancellations. It should be remarked that Oliver Obst calculates that this method underestimates actual 
usage by 15 to 33 percent. ${ }^{5}$ However, as this was the method we have been using for the years to count print uses, we are reluctant to modify our statistics without additional evidence that use is indeed underestimated

One access to a full-text article counted as one use for e-journals. E-journal use statistics are added to the database, in a separate field, as they become available. In this way, librarians can track changes in usage patterns for each title over a multiyear period. A full explanation of the journal use database and statistics collection process is available in Betty Galbraith's2002 article “Journal Retention Decisions Incorporating Use-Statistics as a Measure of Value." ${ }^{\prime 6}$ Here, there also may be a problem of inflated numbers. According to Obst, redundant multiple accesses of between 20 and 28.2 percent have been reported. ${ }^{7}$ Instead of printing articles for future use, our clientele may be going back to the Web site to view the full text time after time. Although anecdotal evidence based on comments from our patrons suggests that Obst is correct, we do not have sufficient data necessary to change our method of reporting uses.
As in the previous article, the authors looked at several questions related to the use of journals during the 2001-2003 study. These results were then compared with the 1998-2001 study. Each question is listed in the results section of the paper, with our analysis following.

\section{Results and Discussion}

How did the total uses of journals in both formats change between 2001 and 2003, and how did that compare to the changes in print use between 1998 and 2003? The most telling indictor of the usage trends at the WSU Libraries is the percent of total uses in each format. In 1998, WSU had no electronic titles and thus no electronic uses. Three years later, 71 percent of the uses were of the electronic format. Just two years after that, electronic use had jumped to 94 percent of all journal uses. Part of this is due to the sheer number of articles viewed in electronic format. Because it is so easy to look at an article from home or the lab, the journals were used more often. But this does not tell much about the use of print journals because the walk-in use of the collection is overshadowed by use of electronic formats.

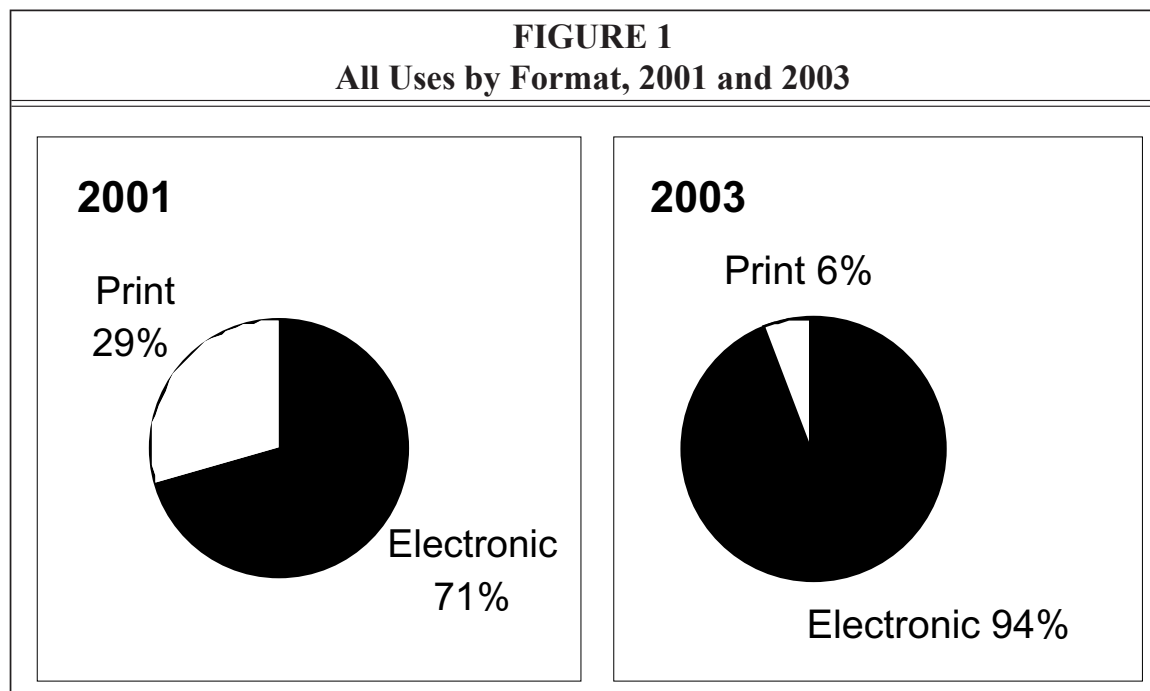

Note: In 2001, nearly one third of recorded journal uses were of print materials. By 2003, although 52 percent of the sample had print available (print-only or both electronic and print formats), print use accounted for only 6 percent of all recorded use. 
How did the use of print titles change between the 1998-2001 study and 2003? Print use dropped significantly, and electronic use skyrocketed based on total use statistics. (See figure 1.) But looking at the collection title by title shows some interesting trends. Most suggestive is that, although electronic use increased significantly, not all journals saw a decrease in print use. Between 2001 and 2003, 14 percent of the titles in this study had increases in print use and 4 percent had no change in the total print uses. (See table 3.) But the rate at which print journal use is increasing is definitely slowing in those titles that saw an increase in print use between 2001 and 2003.

Of the 24 titles that saw increases in print use between 2001 and 2003, only 8 were print only. (See table 4.) The numbers were slightly higher for the changes seen between 1998 and 2003. In fact, most increases in use of the print versions between 2001 and 2003 were in titles that were available in 2003 in either both formats or e-only format. Most of the printonly journals remaining from the original sample were in the MME discipline and, as expected, this area saw the largest numbers of increases in print use across the time period. Although 43 percent of the MME journals were print only, they accounted for only 13 percent of the total journal uses in MME. An informal survey of MME faculty revealed that faculty and students in that area prefer electronic access so that they do not have to leave their labs or offices. Most print use increases for MME were for journals that are also electronic, once again suggesting that there is something important in the print version of the journals.

This increase of print use in currently print and electronic or e-only titles could indicate the continued use of older literature. Perhaps graphics quality or other format limitations of the electronic versions were not adequate to meet the needs of the readers. Another possibility is that the electronic version did not include something in the print volume (e.g., supplements and letters to the editor). Moreover, faculty have told librarians that browsing the print journal collections to see the breadth and depth of interests in each subject area is more convenient than browsing the electronic versions.

\begin{tabular}{|c|c|c|c|c|c|c|c|}
\hline & & & $\begin{array}{r}\text { TAB } \\
\text { anges ir }\end{array}$ & $\begin{array}{l}\text { E } 3 \\
\text { Print Use }\end{array}$ & & & \\
\hline 2001-2003 & & & & & & & \\
\hline & Print & crease & Print 1 & crease & No $C$ & ange & Titles in \\
\hline & $\begin{array}{l}\text { No. of } \\
\text { Titles }\end{array}$ & Percent & $\begin{array}{l}\text { No. of } \\
\text { Titles }\end{array}$ & Percent & $\begin{array}{l}\text { No. of } \\
\text { Titles }\end{array}$ & Percent & \\
\hline Chemistry & 7 & $11 \%$ & 57 & $86 \%$ & 2 & $3 \%$ & 66 \\
\hline MME & 11 & $24 \%$ & 33 & $72 \%$ & 2 & $4 \%$ & 46 \\
\hline Physics & 6 & $9 \%$ & 56 & $86 \%$ & 3 & $5 \%$ & 65 \\
\hline All & 24 & $14 \%$ & 146 & $82 \%$ & 7 & $4 \%$ & 177 \\
\hline 1998-2003 & & & & & & & \\
\hline Chemistry & 11 & $17 \%$ & 55 & $83 \%$ & 0 & $0 \%$ & 66 \\
\hline MME & 15 & $33 \%$ & 31 & $67 \%$ & 0 & $0 \%$ & 46 \\
\hline Physics & 8 & $12 \%$ & 54 & $83 \%$ & 3 & $5 \%$ & 65 \\
\hline Total & 34 & $19 \%$ & 140 & $79 \%$ & 3 & $2 \%$ & 177 \\
\hline
\end{tabular}




\begin{tabular}{|c|c|c|c|c|}
\hline \multicolumn{5}{|c|}{$\begin{array}{c}\text { TABLE } 4 \\
\text { Number of Journals, by Format and Discipline, } \\
\text { That Had an Increase in Print Use }\end{array}$} \\
\hline \multicolumn{5}{|l|}{ 2001-2003 } \\
\hline & $\begin{array}{l}\text { Increase in } \\
\text { Print Use }\end{array}$ & $\begin{array}{c}\text { Print Only in } \\
2003\end{array}$ & E-only in 2003 & Both in 2003 \\
\hline Chemistry & 7 & 0 & 5 & 2 \\
\hline MME & 11 & 8 & 1 & 2 \\
\hline Physics & 6 & 0 & 1 & 5 \\
\hline Total & 24 & 8 & 7 & 9 \\
\hline \multicolumn{5}{|l|}{ 1998-2003 } \\
\hline Chemistry & 11 & 1 & 5 & 5 \\
\hline MME & 15 & 8 & 5 & 2 \\
\hline Physics & 8 & 0 & 5 & 3 \\
\hline Total & 34 & 9 & 15 & 10 \\
\hline \multicolumn{5}{|c|}{$\begin{array}{l}\text { Note: Different disciplines show different percentages of increases in print use of print-only, elec- } \\
\text { tronic-only, and dual-format journals. In recent years, most increases in print use were seen in titles } \\
\text { that had electronic format available. }\end{array}$} \\
\hline
\end{tabular}

We looked at the individual titles that increased in print use in each study to see what that could tell us.

In chemistry, Electrophoresis stood out as having the highest print use increase over the two studies, with 55 more uses in 2001 than in 1998 and 14 more uses in 2003 than in 2001. This may be attributed to multidisciplinary interest in the topics covered by the journal. Similarly, Helvetica Chimica Acta, demonstrated no change in print use, most likely due to its multidisciplinary coverage of chemistry topics.

The reasons behind the print use patterns of MME titles are not clear. Retirements over the time frame of this study would not have impacted these particular titles. New faculty research and teaching interests would not have increased the use of these titles. There was a significant increase in student enrollment and grant proposals between 1998 and 2001, which may explain a portion of the increased use.

A conversation with the physics department faculty member who serves as the library liaison shed some light on the use patterns observed in that discipline. Tribology Letters is among the titles with most consistent print usage, and it was noted that it is used primarily by two faculty members who bring in substantial grant money. In the case of the Bulletin of

\section{TABLE 5}

Number of Titles in Sample Accessed Via SFX, by Discipline, 2003

\begin{tabular}{|l|l|l|l|}
\hline \hline & \multicolumn{1}{|c|}{$\begin{array}{c}\text { Available } \\
\text { Electronically }\end{array}$} & Accessed via SFX & Percentage \\
\hline Chemistry & 62 & 21 & $33.9 \%$ \\
\hline MME & 27 & 8 & $29.6 \%$ \\
\hline Physics & 64 & 18 & $28.1 \%$ \\
\hline $\begin{array}{l}\text { Note: The percentage of each discipline's titles accessed using the SFX link-resolving tool. All three } \\
\text { disciplines had about the same percentage of titles accessed via SFX. }\end{array}$ \\
\hline
\end{tabular}


the American Physical Society, the liaison thought that the online abstracts are nearly useless and that the content found in the print version is necessary for complete understanding. Part of its consistent use also could be explained by the expansion in the number of physicists in recent years and the fact that two members of the faculty were more likely to use paper versions of all library materials.

How did early implementation of a link-resolving tool affect electronic journal use? At the time of 2003 data collection, the WSU Libraries had just completed the first year of use of ExLibris' SFX link resolver. Although a significant percentage of journal titles in each discipline were accessed using SFX, the overall percentage of total use was negligible. (See tables 5 and 6.) This was surprising. It was expected that access to this tool would account for much more of the electronic use than evidenced.

According to usability studies of SFX done at WSU, ${ }^{8}$ the linker was difficult to find or use in the databases most heavily used by the disciplines covered in this study. Shortly after these data were collected, the tool was renamed Find It (instead of using the default name SFX) in the hope that this would indicate to patrons what the button or link would do.

One point of note is that MME had the lowest number of titles available through SFX but showed the highest percentage of total uses facilitated by SFX. The MME faculty indicated, in informal conversations with the authors, that students and faculty in the discipline are generally more comfortable with software and technology. One faculty member stated that everything he needed was on the Internet. Another said that the whole process of going to the library, retrieving the items wanted, and buying a copy card was too burdensome to fit into his busy schedule. All three statements seem to support the idea that these users were more likely to click on a link or button not knowing what it would do, and the data clearly show that users of MME titles were early adopters of the SFX link resolver.

How did the average (mean) use per journal title change over the time

\begin{tabular}{|l|r|r|r|r|}
\hline \multicolumn{5}{|c|}{ TABLE 7 } \\
Average (mean) Use per Title, all Formats, \\
by Discipline \\
\hline \hline
\end{tabular}

Note: The average uses per title in each discipline have increased significantly since e-journals were made available. period of the study? Average use per title jumped significantly across all disciplines over the course of the study. (See table 7.)

This could have several explanations. First, the availability of electronic format for many titles allows users to access materials from their home or office, outside scheduled library open hours, as many times as necessary during the course of their research. 
Improvements in the publishers' interfaces to e-journals and the availability of consistent formats have increased ease of use. Also, journal cancellations during this time focused on less-used titles and those with higher cost-per-use. There also was an effort to cancel paper in favor of electronic access to reduce costs without significantly decreasing the quantity of journals available for our faculty and students.

Between 2001 and 2003, the average use of chemistry titles increased by 83 percent, and physics uses increased by 106 percent. Once again, we see that MME lagged behind with an increase of only 70 percent. The total increase in uses of journals, in all formats, from 1998 to 2003 was 746 percent. One factor that must be noted is that the rate of increase in use of journals has slowed since the last study. Between 1998 and 2001, total uses had increased by 394 percent, but between 2001 and 2003 uses only increased 189 percent. This suggests that use patterns are stabilizing into a new norm. The authors believe that as more and more indexes work with the SFX link resolver, and after the SFX button was renamed Find It, there may be yet another leap in use.

Did changes in gate count correlate with changes in use of print collections? Yes, but not to the degree that the changes in use patterns would suggest. (See figure 2.) The gate count in 2003 was 59 percent of what it was in 1998. By 2003, print journal use declined to 43 percent of 1998 levels. However, overall journal use in both formats increased by 746 percent during the same time period. Librarians have observed patrons using e-journals in the library, and although print book collections are not as heavily used in the sciences as they are in the humanities, some of the difference could be explained by the on-site use of books and other print resources. In addition, many patrons now visit the library to use public computers to check e-mail, submit coursework, register for classes, and conduct other academic and personal business that goes beyond traditional library research.

\section{Individual Subject Areas}

Our study showed a shift in use from print versions to electronic versions in all three disciplines examined.

\section{Chemistry}

Between 2001 and 2003, no new print chemistry titles were added to the collection, but electronic access was added to some titles from the old study. (See figure 3.) Of the 66 chemistry titles, 39 percent were available in both electronic and print formats. Although 45 percent of titles had print available, print-only titles accounted for just 6 percent of the sample of 66 titles. Of the titles still available in print, 23 percent exhibited an increase in print use, although none of these increases were seen in the print-only titles. (See table 4.)

An examination of use of chemistry journals showed that only 5 percent of the total use in the chemistry discipline could be attributed to the print collection,

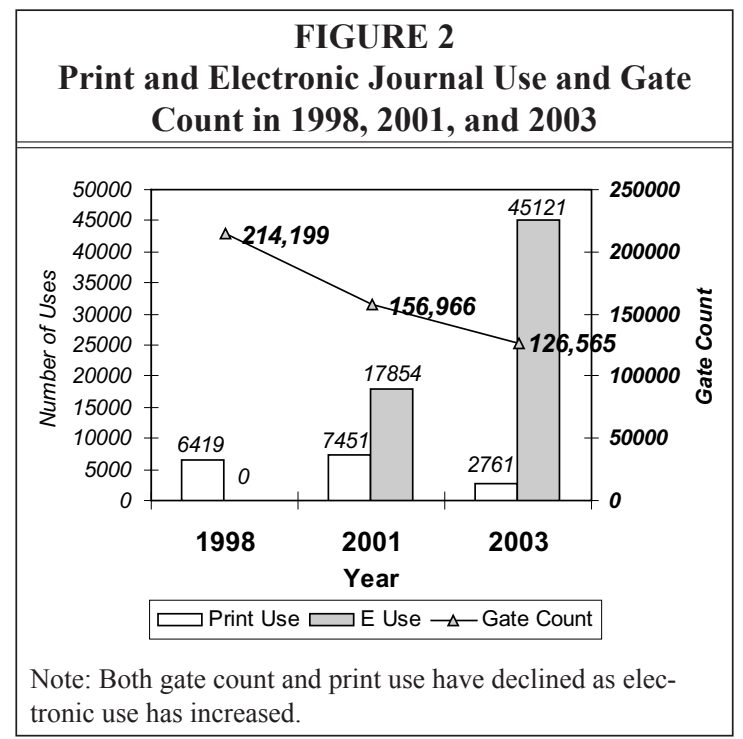




\begin{tabular}{|l|l|}
\hline & FIGURE 3 \\
\hline & Chemistry Uses by Format, 2001 and 2003 \\
\hline 2001 & Erint 25\% \\
\hline
\end{tabular}

a drop from 25 percent of total uses seen in 2001. Electronic access was available for 94 percent of the collection and e-use constituted 95 percent of total use.

\section{Mechanical and Materials Engineering}

Between 2001 and 2003, no new print MME titles were added, but electronic access was made available to some titles from the old study. (See figure 4.) The remaining printonly titles accounted for 43 percent of the 2003 sample. In addition, 23 percent of the titles had both print and electronic access. Of the titles that still had print versions, a still significant 35 percent exhibited an increase in print use compared to 58 percent from the 1998-2001 study.

The examination of total usage revealed that only 13 percent of the uses in the MME discipline could be attributed to the print collection, a drop from 40 percent in 2001. This is despite the fact that 67 percent of the titles had print format available, of which 43 percent remained

\section{FIGURE 4}

MME Uses by Format, 2001 and 2003

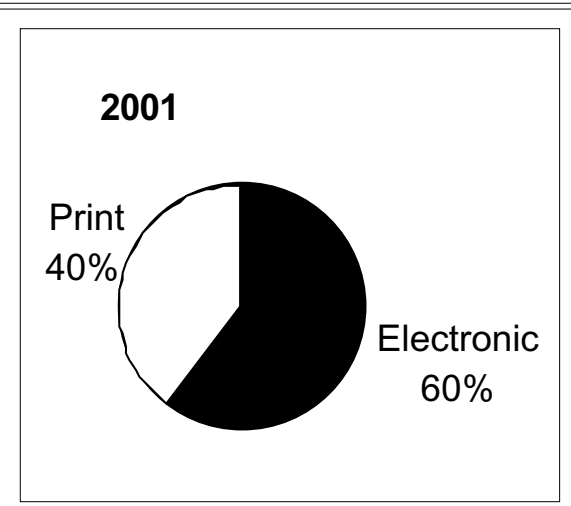

\section{3}

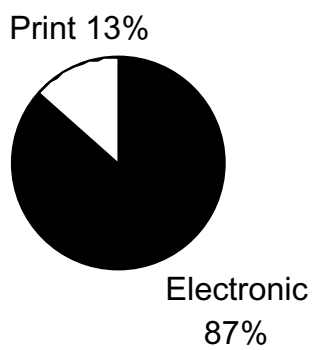

Note: Electronic use of MME titles has increased. Journals with print format available (print-only or both formats) comprise 67 percent of the sample. In 2003, print use accounted for only 13 percent of total use. 


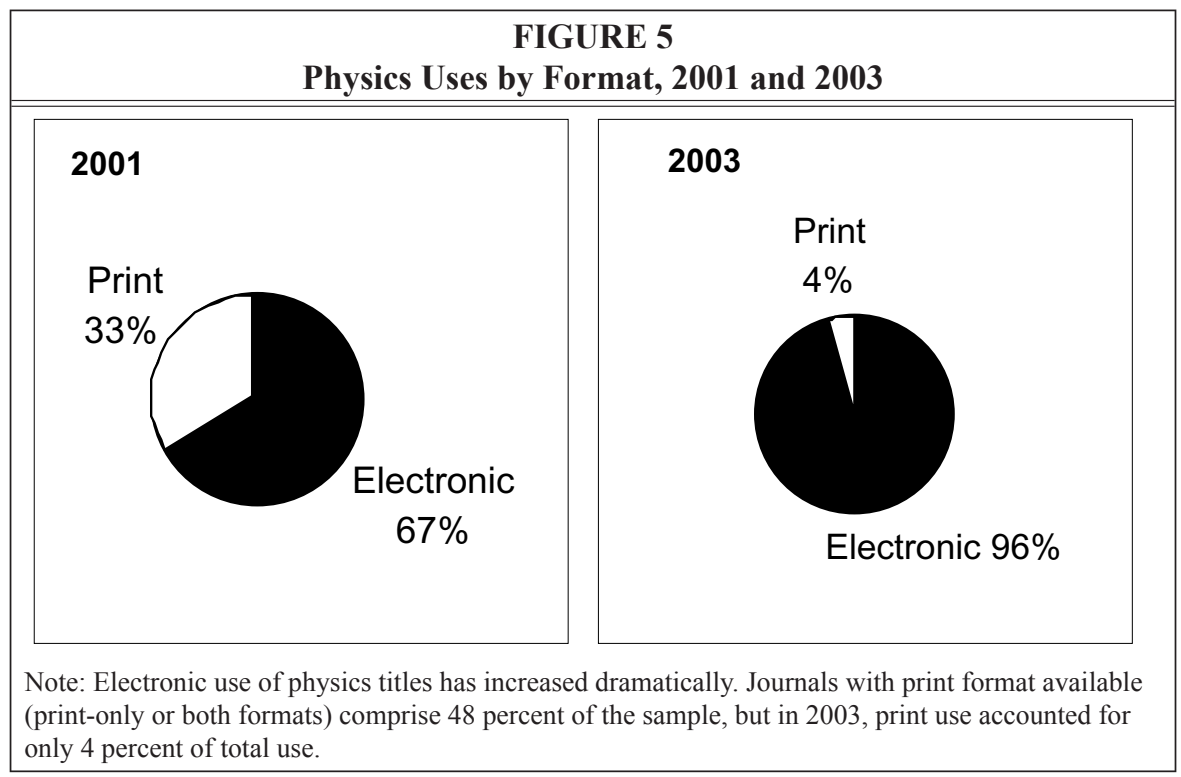

in print-only format. With electronic access available for only 59 percent of the collection, 87 percent of the use was of the electronic format. We feel that we are definitely seeing the point where the users moved from print to electronic as their primary format.

The informal survey of MME faculty indicated that ease of use of e-journals is a major deciding factor. One fact that supports this supposition is that although MME had a lower percentage of titles available through SFX, a higher percentage of journals in this discipline were accessed using SFX.

\section{Physics}

Physics demonstrated the biggest shift in use of the three subject areas studied. Between 2001 and 2003, no new print physics titles were added to the collection, but electronic access was added to some titles from the old study. (See figure 5.) There was only one print-only title in the sample of 65 titles. Fortyeight percent of physics titles were available in both electronic and print formats. Of the titles still available in print, 19 percent exhibited an increase in print use between 2001 and 2003. Once again, when total usage was examined, only 4 percent could be attributed to the print collection. Electronic access was available for 99 percent of the collection and e-use constituted 96 percent of total use.

\section{Conclusions}

Between the two studies, we have caught a cultural shift in process. Although the initial use of paper journals increased with the advent of e-journals, a shift in use patterns occurred to favor electronic format and now 94 percent of all journal use in these disciplines is via electronic format. The use of SFX, although unimpressive in the year data were collected, has contributed slightly to this change. Perhaps the collections budget reduction strategy that targeted print journals forced some of this shift. K. T. L. Vaughn suggested that another reason could be that it is "becoming easier for many faculty and students to use online journals, in part because of familiarity with online products and the enhanced quality of printout as compared to photocopies." ${ }^{\prime 9}$ Once again, there are disciplinary differences in the use of paper and electronic formats. 


\section{Future Directions for Research}

Additional research needs to be undertaken to determine how journal cancellation affects interlibrary loan. Are costs just being shifted to another library department? Will the link resolver result in a significant increase in use of e-journals in coming years? How do different disciplinary "citation half lives" affect print use? As electronic journal backfiles are purchased, will the use of print collections decline as people use the backfiles from home and office or will older literature that was not "born digital" continue to be used in print format? Another interesting question that still needs to be addressed is how many times a user will open the full text of a journal article now that it is available electronically. When faculty and students were required to come to the library to read the article, the tendency was to photocopy it and take it with them.
We now know that patrons can and do access full-text articles from their office or home more than once to recheck facts. Also, no method has yet been devised to capture electronic uses that are not mediated in some way by the library. For example, patrons use search engines to find electronic copies of articles on personal Web pages maintained by the authors and in institutional repositories. Use patterns also may be affected as libraries transition from just-in-case "ownership" models to just-in-time "access" models through consortial purchases and ILL agreements. These questions barely scratch the surface of the new ways patrons interact with collections. We feel fortunate to have documented this major cultural shift at our institution, and remain curious to see how ideas about "use" will continue to evolve.

\section{Notes}

1. Tammy R. Siebenberg, Betty Galbraith, and Eileen E. Brady, "Print versus Electronic Journal Use in Three Sci/Tech Disciplines: What's Going on Here?" College \& Research Libraries 65, no. 5 (Sept. 2004): 427-38.

2. Sandra L. Degroote and Josephine L. Dorsch, “Online Journals: Impact on Print Journal Usage," Bulletin of the Medical Library Association 84, no. 4 (Oct. 2001): 372-78.

3. David H. Morse and William A. Clintworth, "Comparing Patterns of Print and Electronic Journal Use in an Academic Health Science Library," Issues in Science and Technology Librarianship (fall 2000). Available online from http://www.library.ucsb.edu/isl/00-fall/.

4. Sally A. Rogers, "Electronic Journal Usage at Ohio State University," College \& Research Libraries 62, no. 1 (Jan. 2001): 25-34.

5. Oliver Obst., "Patterns and Costs of Printed and Online Journal Usage," Health Information and Libraries Journal 20, no. 1 (Mar. 2003): 22-32.

6. Betty Galbraith, "Journal Retention Decisions Incorporating Use-Statistics as a Measure of Value," Collection Management 27, no. 1 (2002): 79-90.

7. Obst, "Patterns and Costs of Printed and Online Journal Usage."

8. Joel Cummings and Ryan Johnson, "The Use and Usability of SFX: Context-sensitive Reference Linking," Library Hi Tech 21, no. 1 (2003): 70-84.

9. K.T.L. Vaughan, "Changing Use Patterns of Print Journals in the Digital Age: Impacts of Electronic Equivalents on Print Chemistry Journal Use," Journal of the American Society for Information Science and Technology 54, no.12 (2003): 1140-52. 